\title{
The Role of Mesenchymal Stem Cells in Decreasing Interleukin-12 Human Systemic Lupus Erythematosus
}

\author{
Delfitri Munir ${ }^{1}$, Rodiah Rahmawaty Lubis ${ }^{2}$, Dewi Masyithah Darlan ${ }^{3 *}$, Agung Putra $^{4,5,6}$, Iffan Alif ${ }^{4}$ \\ ${ }^{1}$ Pusat Unggulan IPTEK Tissue Engineering, Faculty of Medicine, Universitas Sumatera Utara, Medan, Indonesia; \\ ${ }^{2}$ Department of Ophthalmology, Faculty of Medicine, Universitas Sumatera Utara, Medan, Indonesia; ${ }^{3}$ Department of \\ Parasitology, Faculty of Medicine, Universitas Sumatera Utara, Medan, Indonesia; ${ }^{4}$ Stem Cell and Cancer Research \\ (SCCR), Medical Faculty, Sultan Agung Islamic University (UNISSULA), Semarang, Indonesia; ${ }^{5}$ Department of Postgraduate \\ Biomedical Science, Medical Faculty, Sultan Agung Islamic University (UNISSULA), Semarang, Indonesia; ${ }^{6}$ Department of \\ Pathological Anatomy, Medical Faculty, Sultan Agung Islamic University (UNISSULA), Semarang, Indonesia
}

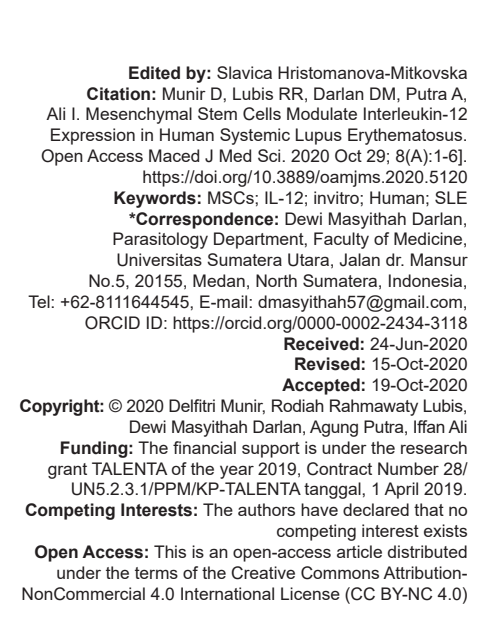

Abstract

BACKGROUND: Systemic lupus erythematosus (SLE) disease is characterized by a loss of self-tolerance leading to a local tissue inflammation up to a massive systemic organ-spesific inflammation. Mesenchymal stem cells (MSCs) present immunomodulatory properties to control the over-activating immune responses in SLE through several mechanisms. However, the capability of MSCs to decrease interleukin (IL)-12 production in in vitro remains unclear. AIM: The aim of this study was to investigate the role of MSCs in decreasing the level of IL-12 derived from peripheral blood mononuclear cells (PBMCs) of SLE patients.

METHODS: This study used a post-test control group design using a coculture of PBMCs from SLE and healthy patients with MSCs as the subjects. This study included five groups: sham (Sh), control (C), and treatment groups (T) treated by a co-culture MSCs with PBMCs at ratio dose of 1:1 (T1), 1:25 (T2), and 1:50 (T3), respectively, for 72 hours of incubation. The IL-12 levels was analysed by cytometric bead array (CBA) of flow cytometry.

RESULTS: This study showed a significant decrease of IL-12 levels $(p<0.05)$ in T1 and T2 after 72 hours incubation of co-culture MSCs with PBMCs from SLE patient.

CONCLUSION: MSCs could decrease the level of IL-12 in PBMCs of human SLE to control the inflammation of SLE disease.

\section{Introduction}

Systemic lupus erythematosus (SLE) is a highly complex and heterogeneous autoimmune disease characterized by a loss of the immune response tolerance to self-antigens that induce an excessive generation of autoantibodies against, immune complex formation, triggering systemic organ-specific inflammation [1]. The host immune responses to these autoantibodyautoantigen complexes depositing into various tissues of the body including renal tissues induce a local inflammatory response up to severe tissue destructions such as lupus nephritis (LN) to renal failure [2]. The persistent risk enhancement of these organ failures' SLE patients mortality trend, making SLE treatment by controlling the initial inflammation processes, is a challenge [3]. On the other hand, interleukin 12 (IL-12) was involved in the $\mathrm{LN}$ development by inducing the T-cells to actively release the inflammatory mediators, thus decreasing the IL-12 level associated with LN's immprovement in the SLE diseases [4]. Mesenchymal stem cells (MSCs) have a robust immunosupressive capability to inflammatory cells, and therefore, the MSCs was assumed to be potentially controlling the initial f SLE by suppressing IL-12. [5].

Mesenchymal stem cells (MSCs) represent a heterogeneous population of fibroblast-like multipotent cells derived from various sources, including umbilical cord (UC), bone marrow, dental pulp, and adipose tissues. These cells have the ability to differentiate into tissues of mesodermal lineage and are characterized by the high expression of several surface antigens, such as CD90, CD105, CD44, and CD73, and lack of expression of CD79 or CD19, CD14 or CD11b, CD45, CD34, and HLA-DR [5]. Nowadays, MSC populations are being extensively investigated for their immunomodulatory properties. A previous study reported that MSC transplantation had a therapeutic effect on various autoimmune diseases, including SLE. The one reasoning use of MSCs to SLE studies is their ability to hamper an excessive inflammation 
by enhancing the regulatory lymphocyte cells (Treg) modulation [7,8]. The functional Treg can release several anti-inflammatory cytokines that to inhibit the autoreactive $\mathrm{T}$ cells including $\mathrm{T}$ helper 1 (Th1) cell activation by downregulation of IL-12 [5], [9].

As one of the pro-inflammatory cytokines released by antigen-presenting cells (APCs), such as macrophages and dendritic cells (DCs), IL-12 is responsible for mediating adaptive immune response, particularly Th1 cells [10]. Several studies have reported that the overexpression of IL-12 in SLE diseases can massively induce the differentiation of naive Th into Th1 cells leading to the inflammatory niche formation in renal, known as the LN disease [11,12]. On the other hand, a recent study also revealed that MSCs have the suppressive capability to control several autoimmune cells, including in SLE diseases, by enhancing the functionality of the Treg subset [13]. The activation of functional Treg along with MSCs can suppress the most inflammatory cells including in releasing IL-12 on APCs mechanism resulting in the decrease of the naïve CD4 Th differentiation to Th1 that is correlated with the the improvement of inflammatory tissues [14], [15], [16]. However, capability of human MSCs to decrease IL-12 production in peripheral blood mononuclear cells (PBMCs) from SLE patients in vitro remains unclear. Hence, this study we investigated to the role of MSCs in decreasing the level of IL-12 derived from PBMCs of SLE patients in vitro.

\section{Materials and Methods}

\section{Lupus patients and healthy subjects}

This study was conducted in the Stem Cell and Cancer Research (SCCR) Laboratory, Faculty of Medicine, Sultan Agung Islamic University, Semarang, in September-October 2019. In total, 20 SLE patients from Kariadi Hospital and 5 healthy subjects were included in this study. Specific informed consent was obtained from each subject for peripheral blood and UC collection. This study was approved by and conducted in accordance with the review board of the Health Research Ethical Committee Medical Faculty of Universitas Sumatera Utara (USU), Medan, under No. 698/TGL/KEPK FK USU-RSUP HAM/2019.

The participants were divided into five groups: Negative and positive control groups were treated with standard medium, and the treatment group was cocultured with human UC-MSC at doses of 1:1, 1:25, and 1:50 (MSCs:peripheral blood mononuclear cells [PBMCs]).

\section{MSC isolation}

MSCs were isolated from fresh Wharton jelly of the UC obtained from healthy mothers in the local maternity hospital with specific informed consent. The isolation and expansion process was carried out as described previously [17]. Briefly, the cords were rinsed using phosphate-buffered saline (PBS) (Gibco ${ }^{\mathrm{TM}}$ Invitrogen, NY, USA), and cord blood was removed. The washed cords were cut into smaller pieces; transferred to a T25 culture flask (Corning, Tewksbury, MA, USA) containing Dulbecco's Modified Eagle Medium (DMEM) (Sigma-Aldrich, Louis St., MO); supplemented with 10\% fetal bovine serum (FBS) (Gibco ${ }^{\mathrm{TM}}$ Invitrogen, NY, USA), $1 \%$ penicillin $(100 \mathrm{U} / \mathrm{mL}) /$ streptomycin $(100 \mu \mathrm{g} / \mathrm{mL})$ (Gibco ${ }^{\mathrm{TM}}$ Invitrogen, NY, USA), and $0.25 \%$ amphotericin $\mathrm{B}$ (Gibco ${ }^{\mathrm{TM}}$ Invitrogen, NY, USA); and incubated at $37^{\circ} \mathrm{C}$ in a humid atmosphere consisting of $5 \% \mathrm{CO}_{2}$. The medium was renewed every 3 days. Non-adherent cells were removed by washing. After fibroblast-like cells appeared and reached $80 \%$ confluence (14 days), the cells were trypsinized and transferred into a new flask for further expansion. The cells derived from passage 5 were used for the following experiments.

\section{Flow cytometry analysis of MSCs}

MSC-like surface markers were assessed by flow cytometry analysis at passage 5 according to the manufacturer's instructions. MSC-like cells were trypsinized and pelleted by centrifugation at $1900 \mathrm{rpm}$ for $8 \mathrm{~min}$. The supernatant was removed, and pelleted cells were washed using PBS. Approximately $1 \times 10^{5}$ detached cells were resuspended in $100 \mu$ l staining buffer (BD Bioscience, San Jose, CA, USA). For the staining of surface antigens, the cells were subsequently incubated using fluorescein isothiocyanate-, allophycocyanin (APC)-, peridinin-chlorophyll-protein (perCP)-Cy ${ }^{\mathrm{TM}} 5.5 .1$, and phycoerythrin (PE)-conjugated anti-human CD90, CD73, CD105, and Lin (CD45/CD34/ CD11b/CD19/HLA-DR) antibodies (BD Bioscience, San Jose, CA, USA) for $30 \mathrm{~min}$ at room temperature in the dark. In addition, an appropriate isotype-specific conjugated anti-IgG (BD Bioscience, San Jose, CA, USA) was used as the negative control. Unstained cells were also used to determine a threshold. Each sample was washed twice using PBS, and the analysis was performed using a BD Accuri C6 Plus flow cytometer (BD Bioscience, San Jose, CA, USA). A minimum of 1 $\times 10^{4}$ gated events on forward scatter and side scatter was recorded for each sample. Finally, post-acquisition analysis was conducted using BD Accuri C6 Plus software (BD Bioscience, San Jose, CA, USA).

\section{In vitro osteogenic differentiation assay}

The MSC-like cells were cultured at a density of $1 \times 10^{4}$ cells/well in a 24 -well plate with standard medium containing DMEM, 10\% FBS, 1\% penicillin (100 U/mL)/ streptomycin $(100 \mu \mathrm{g} / \mathrm{mL})$, and $0.25 \%$ amphotericin B. The cells were incubated at $37^{\circ} \mathrm{C}, 5 \% \mathrm{CO}_{2}$, and $\geq 95 \%$ humidity. After $95 \%$ confluency was reached, the standard medium was replaced with an osteogenic 
differentiation medium containing Human MesenCult ${ }^{\mathrm{TM}}$ Osteogenic Differentiation Basal Medium (Stem Cell Technologies, Singapore), supplemented with $20 \%$ Human MesenCult ${ }^{\mathrm{TM}}$ Osteogenic Differentiation 5X Supplement (Stem Cell Technologies, Singapore), and $1 \%$ L-glutamine (Gibco ${ }^{\mathrm{TM}}$ Invitrogen, NY, USA). The differentiation medium was renewed every 3 days. After bone matrix formation occurred, osteogenic differentiation was visualized by adding $1 \mathrm{ml}$ of $2 \%$ alizarin red solution (w/v) $(\mathrm{pH} 4.1-4.3)$. The cells were incubated at $37^{\circ} \mathrm{C}$ for $30 \mathrm{~min}$, then washed 4 times in distilled water.

\section{PBMCs Isolation and MSCs treatment in co-culture of PBMCs}

Human PBMCs were isolated from 20 active SLE patients and 5 healthy controls at the same point using Ficoll-Paque (Sigma-Aldrich, Louis St., MO) density gradient centrifugation with specific informed consent. The separated buffy coat layer containing PBMCs was collected, washed, and pelleted by centrifugation at $1900 \mathrm{rpm}$ for $8 \mathrm{~min}$. Then, PBMCs were cultured in $2 \mathrm{ml}$ of advanced RPMI 1640 culture medium (Gibco ${ }^{\mathrm{TM}}$ Invitrogen, NY, USA); supplemented with $10 \% \mathrm{FBS}, 100 \mathrm{U} / \mathrm{ml}$ penicillin and streptomycin, and $2 \mathrm{mM}$ glutamine; and incubated at $37^{\circ} \mathrm{C}$ in a humidified atmosphere with $5 \% \mathrm{CO}_{2}$. After $24 \mathrm{~h}$ of incubation, for the treatment group, PBMCs were cocultured with MSCs using a Corning Costar $0.4 \mu \mathrm{m}$ Transwell cell culture plate in RPMI supplemented with $10 \%$ FBS, $1 \%$ penicillin-streptomycin, and $0.25 \%$ amphotericin $B$ at an MSC to PBMC ratio of 1:1, 1:25, and 1:50 (T1, T2, and $\mathrm{T} 3$, respectively) for $72 \mathrm{~h}$. On the other hand, for the negative and positive control groups, the isolated PBMCs from healthy and SLE patients, respectively, were cultured in another well plate with standard medium for $72 \mathrm{~h}$.

\section{Determination of IL-12 level}

After $72 \mathrm{~h}$, the coculture supernatants were analyzed using the Human IL-12/IL-23p40 Flex Set (560154, BD Biosciences, San Jose, CA, USA) according to the manufacturer's instructions. Cell culture supernatants were collected and frozen at $-80^{\circ} \mathrm{C}$ for cytometric bead array (CBA) measurement. After acquisition of sample data using BD Accuri C6 Plus Flow Cytometer (BD Biosciences, San Jose, CA, USA), the IL-12 level were calculated using the proprietary FCAP Version 1.0 analysis software (BD Biosciences, San Jose, CA, USA).

\section{Data analysis}

Values were presented as the mean \pm SE. All calculations were carried out using SPSS 23.0 (IBM Corp., Armonk, NY, USA). Group comparisons were analyzed by ANOVA, followed by post hoc Fisher's LSD. $p<0.05$ was considered statistically significant.

\section{Results}

\section{Isolation and differentiation of MSCs}

MSC-like cells were isolated from UC and cultured based on their plastic adherent capability. The isolated cells were grown for 2 weeks in a monolayer until they reached $80 \%$ confluence and were employed for differentiation analysis after passage 5 . The adherent cells cultured in standard medium showed fibroblastic morphology (spindle shaped) with multiple nucleoli, which is a typical characteristic of MSCs (Figure 1a). Furthermore, MSCs were also cultured in osteogenic differentiated medium to determine osteogenic differentiation capacity. After 20 days of incubation, the medium was replaced, and calcium deposition was visualized in red color after alizarin red solution administration (Figure $1 \mathrm{~b}$ ). The calcium deposition indicated that MSCs have the capability to differentiate into osteogenic lineage through forming the bone matrix, according to the main criteria defined by the International Society for Cellular Therapy (ISCT).

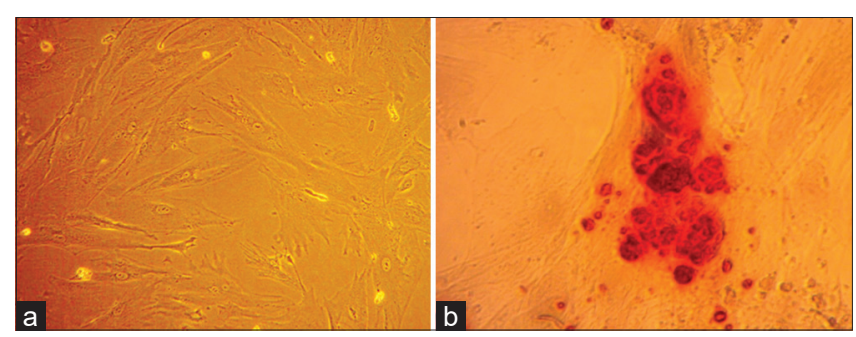

Figure 1: (a) Mesenchymal stem cells like characterized by their fibroblastic characteristic with spindle shape morphology; (b) and calcium deposition was shown in red color by alizarin red staining (200x)

\section{Characteristics of MSCs}

At the end of the fifth passage expansion, MSC-like cells were trypsinized and passaged, and the surface antigens were analyzed using flow cytometry analysis. The specific profiles of MSC antigens are CD73, CD105, CD90, and negative for Lin (CD45/ CD34/CD11b/CD19/HLA-DR) antibodies in accordance with the ISCT criteria. The result showed that UC-MSCs expressed high levels of CD90 (99.9\%), CD105 (95.9\%), and CD73 (99.2\%) and lacked expression of Lin antibodies (2.0\%) (Figure 2).

\section{with PBMCs}

\section{MSCs enhance IL-12 level after coculture}

Finally, we measured the level of IL-12 after $72 \mathrm{~h}$ of coculture between MSCs and SLE PBMCs. 

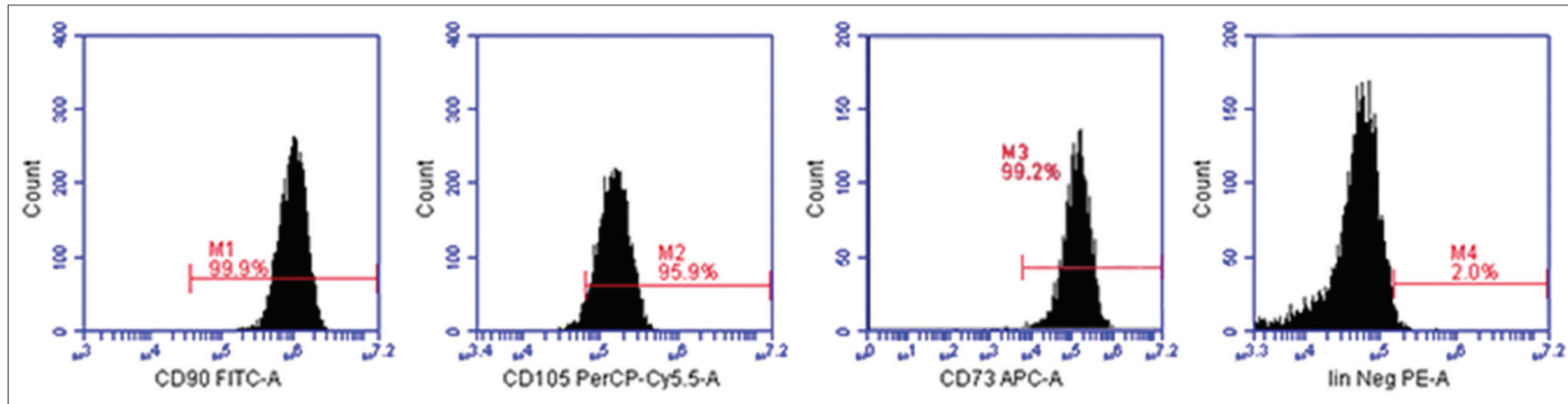

Figure 2: Immunophenotyping analysis of mesenchymal stem cells which was positive for CD73, CD90, and CD105 and negative for Lin

We collected the coculture medium from treatment groups and the PBMC culture medium from negative and positive control groups. The CBA assay showed a significant increase in the II-12 level in the T1 and T2 groups $(p<0.05)$. In T1 and T2, the IL-12 level was noted at $24.99 \pm 5.35$ and $27.77 \pm 9.03 \mathrm{pg} / \mathrm{mL}$, respectively (Figure 3 ).

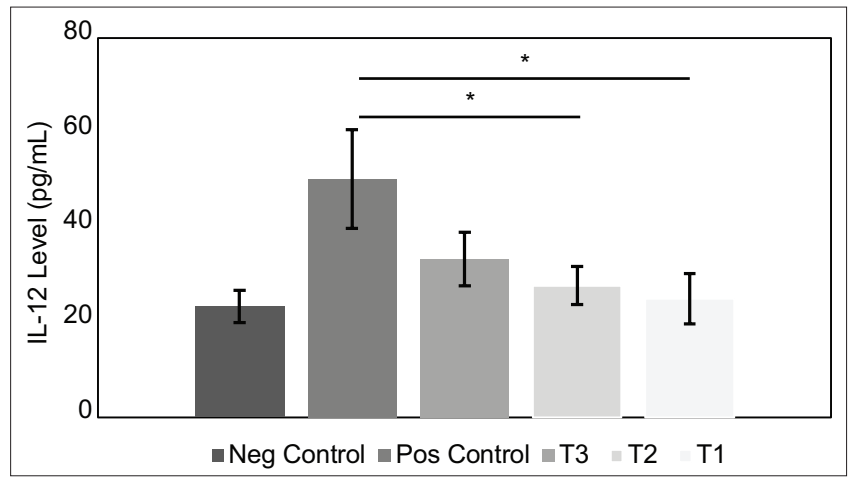

Figure 3: Mesenchymal stem cells (MSCs) decrease the IL-12 level in coculture between MSCs and peripheral blood mononuclear cells with SLE. After $72 \mathrm{~h}$ incubation, the cytometric bead array assay was used to determine the level of IL-12 in coculture system. The level of II-12 was significantly decrease in T1 and T2 compared to control group. $\left({ }^{*} p<0.05\right)$

\section{Discussion}

MSCs' capability to decrease the activation of the most proinflammatory-related Th cells has opened up a new understanding of SLE disease's. The MSCs capacity to suppress the proinflammatory condition in SLE depending on their responses to the type of immune cells, whether by inhibiting or modulating the immune cells [7], [8]. The one mechanisms of MSCs in controlling the inflammation is by suppressing the activated APC such as macrophage and DCs in releasing IL-12 to communicate with T-cell populations [10], [12].

However,

the

MSC-mediated immunosuppression to PBMCs derived from human SLE specifically in decreasing IL-12 levels remain incompletely understood. Here, we revealed the capacity of human MSCs to decrease the level of IL-12, one of the suppress cytokines involved in the differentiation of naive Th into Th-1 cells.

This study demonstrated that MSCs could inhibit the pro-inflammatory niche by suppressing IL-12 significantly, a pro-inflammatory cytokine involved in robust Th1 expansion. We found that the IL-12 level was significantly decreased in human SLE PBMCs under 72 hours of co-culture condition with MSCs at doses ratio of MSCs:PBMCs; 1:1 (high doses) and 1:25 (moderate doses): however, there is no differentiation of IL-12 decrease among these doses. These data suggest that MSCs could hamper the robust pro-inflammatory condition of DCs and macrophage cells such as APCs under SLE conditions at only moderate doses. Under a pro-inflammatory niche, MSCs initially enhance TLR3 expression [17] to activate NF-K $\beta$ and ERK pathway of MSCs type-1 however, along with the time, these MSCs were polarized into MSCs type-2 to express TLR4 and to produce IL-10 and TGF- $\beta$ [18].

IL-10 is a major immunosuppressive cytokine involved in the maintenance of a balanced immune response [19]. In SLE conditions, the IL-10 level decreased due to the overactivation of IFN-y-released Th1 and the depletion of Treg [20]. The massive release of IFN- $y$ could be involved in the positive feedback loop to activate APCs, such as macrophage and B cells, leading to the enhancement of several pro-inflammatory cytokine levels, including IL-12 [21]. MSCs could inhibit this robust inflammatory condition by expressing a high level of IL-10 [17,22]. IL-10 has a major role in limiting the extent of both innate and adaptive immune activation [23]. A previous study reported that IL-10 is one of the major negative regulators of TLR-induced IL-12 expression [24]. IL-10 also could suppress both $\| 12 \mathrm{a}$ and $I 112 \mathrm{~b}$ genes at the transcriptional level leading to the suppression of IL-12 level [25]. On the other hand, IL-12 can inhibit the expression of TGF- $\beta$-induced lineage-specific transcription factor FoxP3 to prevent the differentiation of Treg cells [26]. Hence, under high levels of IL-12 in SLE conditions, the production of Treg cells also could be inhibited, leading to the robust expansion of Th1 to result a massive inflammation. However, the MSCs could secrete a high level of TGF- $\beta$ to result in the high generation of Treg cells to suppress 
excessive anti-inflammatory cytokines [27], [28], [29]. These findings suggest that MSCs could regulate the inflammatory condition in human SLE by inhibiting IL-12 expression. However, in our study, we did not explore the APCs, including DCs and macrophages as the cells producing IL-12 to differentiate naive Th into Th1 cells. Therefore, the mechanism MSCs in controlling the IL-12 in SLE disease through APCs pathways remains unclear. We also did not analyze the levels of IL-10 and TGF- $\beta$ as potent anti-inflammatory cytokines and major differentiation factors of Treg in controlling the inflammatory cells in SLE thus the mechanism of MSCs to decrease IL-12 in SLE disease should be further explored.

\section{Conclusion}

In summary, MSCs could inhibit the level of IL-12 in PBMCs of human SLE. Therefore, the continuous naive Th12 differentiation into Th1 in SLE also reduced that is associated with the decrease of Th1-released IFNy leading to the controlled the inflammation. This MSCs capacity could become a great and attractive therapy to control the inflammation of SLE.

\section{Acknowledgments}

The authors gratefully acknowledge that the present research is supported by the Ministry of Research, Technology, and Higher Education of the Republic of Indonesia, and research and community service, USU. We would also like to thank the SCCR Laboratory, Medical Faculty, Sultan Agung Islamic University (Unissula), Semarang, for the facility to finish this research.

\section{References}

1. Bertolaccini ML, Sciascia S, Radin M, Roccatello D, Sanna G. Recent advances in the management of systemic lupus erythematosus. F1000Res. 2018;7:1-17. https://doi. org/10.12688/f1000research.13941.1

PMid:30026918

2. Moulton VR, Suarez-FueyoA, Meidan E, LiH, Mizui M, Tsokos GC. Pathogenesis of human systemic lupus erythematosus: A cellular perspective. Trends Mol Med. 2017;23(7):615-35. https://doi.org/10.1016/j.molmed.2017.05.006 PMid:28623084

3. Stojan G, Petri M. Epidemiology of systemic lupus erythematosus: An update. Curr Opin Rheumatol. 2018;30(2):144-50.

\section{PMid:29251660}

4. Larosa M, Zen M, Gatto M, Jesus D, Zanatta E, laccarino L, et al. IL-12 and IL-23/Th17 axis in systemic lupus erythematosus. Exp Biol Med (Maywood). 2019;244(1):42-51.

PMid:30664357

5. Cheng RJ, Xiong AJ, Li YH, Pan SY, Zhang QP, Zhao Y, et al. Mesenchymal stem cells: Allogeneic MSC may be immunosuppressive but autologous MSC are dysfunctional in lupus patients. Front Cell Dev Biol. 2019;7:1-13. https://doi. org/10.3389/fcell.2019.00285

PMid:31799252

6. Rastegar F, Shenaq D, Huang J, Zhang W, Zhang BQ, He BC, et al. Mesenchymal stem cells: Molecular characteristics and clinical applications. World J Stem Cells. 2010;2(24):67-80. PMid:21607123

7. Darlan DM, Munir D, Putra A, Jusuf NK. MSCs-released TGF 31 generate CD4+CD25+Foxp3+ in T-reg cells of human SLE PBMC. J Formos Med Assoc. 2020;40:1-7. https://doi. org/10.1016/j.jma.2020.06.028

8. Ikhsan R, Putra A, Munir D, Darlan DM, Suntoko B, Retno A. Mesenchymal stem cells induce regulatory T-cell population in human SLE. Bangladesh J Med Sci. 2020;19(4):743-8. https:// doi.org/10.3329/bjms.v19i4.46635

9. Luz-Crawford $P$, Kurte $M$, Bravo-Alegría J, Contreras $R$, Nova-Lamperti E, Tejedor G, et al. Mesenchymal stem cells generate a CD4+CD25+Foxp3+ regulatory $\mathrm{T}$ cell population during the differentiation process of Th1 and Th17 cells. Stem Cell Res Ther. 2013;4(3):65. https://doi.org/10.1186/scrt216 PMid:23734780

10. Larosa M, laccarino L, Gatto M, Punzi L, Doria A. Advances in the diagnosis and classification of systemic lupus erythematosus. Expert Rev Clin Immunol. 2016;12(12):1309$20 . \quad$ https://doi.org/10.1080/1744666x.2016.1206470 PMid:27362864

11. Noble A, Thomas MJ, Michael Kemeny D. Early Th1/Th2 cell polarizationintheabsenceofIL-4andIL-12:Tcellreceptorsignaling regulates the response to cytokines in CD4 and CD8 T cells. Eur J Immunol. 2001;31(7):2227-35. https://doi.org/10.1002/15214141(200107)31:7<2227::aid-immu2227>3.0.co;2-c PMid: 11449377

12. NembriniC,AbelB,KopfM,MarslandBJ.StrongTCRsignaling,TLR ligands, and cytokine redundancies ensure robust development of Type 1 effector T cells. J Immunol. 2006;176(12):71808. $\quad$ https://doi.org/10.4049/jimmunol.176.12.7180 PMid: 16751361

13. Buckner $\mathrm{JH}$. Mechanisms of impaired regulation by $\mathrm{CD} 4(+)$ CD25(+)FOXP3(+) regulatory $\mathrm{T}$ cells in human autoimmune diseases. Nat Rev Immunol. 2010;10(12):849-59. https://doi. org/10.1038/nri2889 PMid:21107346

14. Trinchieri G. Interleukin-12 and the regulation of innate resistance and adaptive immunity. Nat Rev Immunol. 2003;3(2):133-46. https://doi.org/10.1038/nri1001 PMid:12563297

15. Lauwerys BR, Van Snick J, Houssiau FA. Serum IL-12 in systemic lupus erythematosus: Absence of $\mathrm{p} 70$ heterodimers but presence of p40 monomers correlating with disease activity. Lupus. 2002;11(6):384-7. https://doi.org/10.1191/0961203302/u213oa PMid:12139377

16. Miteva LD, Manolova IM, Ivanova MG, Rashkov RK, Stoilov RM, Gulubova MV, et al. Functional genetic polymorphisms in interleukin-12B gene in association with systemic lupus erythematosus. Rheumatol Int. 2012;32(1):53-9. https://doi. org/10.1007/s00296-010-1547-6

PMid:20658240

17. Putra A, Ridwan FB, Putridewi Al, Kustiyah AR, Wirastuti K 
Sadyah NAC, Rosdiana I, Munir D. The role of tnf- $\alpha$ induced mscs on suppressive inflammation by increasing tgf- $\beta$ and il- 10 . Open Access Maced J Med Sci. 2018;6(10):1779-83. https:// doi.org/10.3889/oamjms.2018.404

PMid:30455748

18. Aksoy E, Taboubi S, Torres D, Delbauve S, Hachani A Whitehead MA, et al. The p1108 isoform of the kinase $\mathrm{PI}(3)$ $\mathrm{K}$ controls the subcellular compartmentalization of TLR4 signaling and protects from endotoxic shock. Nat Immunol. 2012;13(11):1045-54. https://doi.org/10.1038/ni.2426 PMid:23023391

19. Maynard CL, Weaver CT. Diversity in the contribution of interleukin-10 to T-cell-mediated immune regulation. Immunol Rev. 2008;226:219-23. https://doi. org/10.1111/j.1600-065X.2008.00711.X PMid:19161427

20. Godsell J, Rudloff I, Kandane-Rathnayake R, Hoi A, Nold MF, Morand EF, et al. Clinical associations of IL-10 and IL-37 in systemic lupus erythematosus. Sci Rep. 2016;6:1-10. https:// doi.org/10.1038/srep34604

21. Grohmann U, Belladonna ML, Vacca C, Bianchi R, Fallarino F, Orabona $\mathrm{C}$, et al. Positive regulatory role of $\mathrm{IL}-12$ in macrophages and modulation by IFN-gamma. J Immunol. 2001;167(1):221-7. https://doi.org/10.4049/jimmunol.167.1.221 PMid:11418652

22. Muhar AM, Putra A, Warli SM, Munir D. Hypoxia-mesenchymal stem cells inhibit intra-peritoneal adhesions formation by upregulation of the IL-10 expression. Open Access Maced J Med Sci. 2019;7(23):3937-43. https://doi.org/10.3889/ oamjms.2019.713 PMid:32165932

23. Ma X, Yan W, Zheng $\mathrm{H}$, Du Q, Zhang L, Ban $\mathrm{Y}$, et al. Regulation of IL-10 and IL-12 production and function in macrophages and dendritic cells. F1000Res. 2015;4:1. https://doi.org/10.12688/ f1000research.7010.1

\section{PMid:26918147}

24. Rahim SS, Khan N, Boddupalli CS, Hasnain SE, Mukhopadhyay S. Interleukin-10 (IL-10) mediated suppression of IL-12 production in RAW 264.7 cells also involves c-rel transcription factor. Immunology. 2005;114(3):313-21. https://doi. org/10.1111/j.1365-2567.2005.02107.x

PMid: 15720433

25. Smith AM, Qualls JE, O'Brien K, Balouzian L, Johnson PF Schultz-Cherry $S$, et al. A distal enhancer in $1112 \mathrm{~b}$ is the target of transcriptional repression by the STAT3 pathway and requires the basic leucine zipper (B-ZIP) protein NFIL3. J Biol Chem. 2011;286(26):23582-90. https://doi.org/10.1074/jbc. m111.249235

PMid:21566115

26. Prochazkova J, Pokorna K, Holan V. IL-12 inhibits the TGF- $\beta$ dependent $T$ cell developmental programs and skews the TGF- $\beta$ induced differentiation into a Th1-like direction. Immunobiology. 2012;217(1):74-82. https://doi.org/10.1016/j.imbio.2011.07.032 PMid:21903294

27. Darlan DM, Munir D, Jusuf NK, Ikhsan R, Alif I, Putra A. In vitro regulation of IL- 6 and TGF- $\beta$ by mesenchymal stem cells in systemic lupus erythematosus patients. Med Glas (Zenica). 2020;17(2):448-53.

PMid:32602296

28. Marie JC, Letterio JJ, Gavin M, Rudensky AY. TGF-beta1 maintains suppressor function and Foxp3 expression in CD4+CD25+ regulatory T cells. J Exp Med. 2005;201(7):10617. https://doi.org/10.1084/jem.20042276 PMid:15809351

29. Wan YY, Flavell RA. 'Yin-Yang' functions of transforming growth factor-beta and $T$ regulatory cells in immune regulation. Immunol Rev. 2007;220(1):199-213. https://doi. org/10.1111/j.1600-065x.2007.00565.x

PMid: 17979848

Author Queries???

AQ1: Kindly cite refernce 6 in the text part and also chronological order. 